\title{
Incidence and Risk factors of Uterine Scar Dehiscence after Previous Caesarean Section
}

\author{
RIZWANA NAZ1 ${ }^{1}$, MARYAM SHOAIB ${ }^{2}$, SAKINA NAEEM ${ }^{3}$, SAMIA SAIFULLAH $^{4}$, SAFIA EWAZ ALI $^{5}$ \\ ${ }^{1}$ Senior Registrar Gynae/Obstetrics, Sandeman Provincial Hospital, Quetta \\ ${ }^{2,3}$ Assistant Professor Gynae/Obstetrics, Sandeman Provincial Hospital, Quetta \\ ${ }^{4}$ Senior Registrar Gynae/Obstetrics, Sandeman Provincial Hospital, Quetta \\ ${ }^{5}$ MBBS, FCPS Gynae/Obstetrics, Sandeman Provincial Hospital, Quetta \\ Corresponding author:Dr. Rizwana Naz, E-mail: riz_nz@hotmail.com
}

\begin{abstract}
Objectives: To assess the incidence and risk factors of scar dehiscence.

Methodology: This was a prospective observational study where a total of 210 patients were involved over a period of six months (May 2020 to November 2020) who came to Sandeman Provincial Hospital, BUMHS gynaecology unit 1. The parturient were above the age of 18 and had previous uncomplicated lower segment caesarean sections. Patients with previous classical caesarean section and ruptured uterus diagnosed pre or intra-operatively were excluded from the study. Sampling technique: Non-probability convenience sampling technique will be used.

Results: In this study, the mean age of the patients was $31.57 \pm 4.26$ years, the mean gestational age was $34.43 \pm 4.45$ weeks. The incidence of scar dehiscence was observed in 47 patients.

Conclusion: Uterine Scar Dehiscence is one of the factors that increases fetal and maternal morbidity and mortality rate. Its incidence is found to be related with $\mathrm{C}$-sections, inadequately short intra-pregnancy time interval, preterm delivery, VBAC and trial labour. In this study, the incidence of scar dehiscence was $22.38 \%$.

Keywords: Previous one caesarean section, scar dehiscence, scar tenderness.
\end{abstract}

\section{INTRODUCTION}

Worldwide, the number of caesarean sections has risen. In the United States, for example, the incidence of CSs has risen from $5.0 \%$ in 1970 to $32.9 \%$ in 2009 [1]. urban population, educated women and wealthy parturients had higher rates of lower segment caesarean sections, which has increased from $2.7 \%$ to $15.8 \%$ from 1990-2013 [1-2]. Caesarean section scar dehiscence (CSSD) is one of the most serious complications of caesarean deliveries [3]. It affects 0.2 to $4.3 \%$ of all pregnancies that have had a previous caesarean section [1]. Scar dehiscence is asymptomatic in $48 \%$ of women and can progress to uterine rupture if not treated [4-6]. 0.07 to $0.1 \%$ of all term pregnancies end in uterine rupture. Cephalopelvic disproportion or transverse posture and grand multiparity may be associated with uterine scar dehiscence. Dehiscence of past $\mathrm{C}$-section scars is the most common cause of uterine rupture [7]. Consequently, scar dehiscence is an extremely dangerous pregnancy complication because it can lead to uterine rupture and major maternal and perinatal morbidity and mortality if it is not predicted in advance. Individual or a combination of clinical circumstances, however, make it difficult to anticipate scar dehiscence [8].

Uterine scar rupture (USR) and dehiscence (USD) are associated with previous cesarean delivery (CD), thus it's not surprising that both conditions have been on the rise in tandem with caesarean delivery rates [3]. According to a study conducted in Pakistan, only $11.1 \%$ of patients who had a previous LSCS were caesarean delivery candidates, although vaginal delivery after caesarean section (VBAC) rates were high $(63.6 \%)$ [9]. Parturients who have had caesarean deliveries are on the increase. Multiple obstetric associations have produced consensus guidelines for the treatment of parturients who have had previous caesarean sections [10-11]. Serosa remains intact and the placenta and umbilical cord remain within the uterine cavity [12], which is the most common type of uterine scar disruption. Usually it is a clinically occult benign condition identified accidentally at ERCD. This study is conducted because we currently lack a method which can reliably predict scar dehiscence.

\section{METHODOLOGY}

After the approval of hospital ethical committee, this prospective observational study was conducted in Sandeman Provincial Hospital Quetta, Gynae Unit 1 from $1^{\text {st }}$ October 2020 till $1^{\text {st }}$ November 2020 . WHO sample size calculator was used to calculate a sample size of 210 cases. Parturient who were undergoing LSCS were randomly selected by non-probability convenient sampling. These included pregnant women above 18 years of age and with history of previous uncomplicated caesarean deliveries undergoing emergency or elective LSCS. Patients with previous classical scar and those having overt signs of uterine rupture like haemorrhage are excluded from the study. Those who did not give consent to participate in the study were also excluded. Their clinical record was reviewed, their demographic profile (age, parity), inter-pregnancy interval, previous number of caesarean sections, scar tenderness etc. were recorded in the pre designed proforma. The outcome were: incidence of scar dehiscence was observed to be $22.38 \%$. The risk factors studied were age, inter-delivery interval, mode of admission, labouring or non-labouring, previous number of LSCS, indication of current caesarean section.

Data analysis: SPSS 20 was used for data analysis. All the quantitative variables like age, inter- delivery interval, previous number of LSCS and incidence were presented as frequency and percentages. Chi-square was used to calculate significance, with $\mathrm{P}$-value $<0.05$, which is statistically significant. 


\section{RESULTS}

\begin{tabular}{|l|l|}
\hline Total No. of Patients: & 210 \\
\hline Duration of study & 6 months \\
\hline Mean Age: & $31.57 \pm 4.26$ years \\
\hline Gestational Age & $34.43 \pm 4.45$ weeks \\
\hline $\begin{array}{l}\text { Frequency of Scar } \\
\text { dehiscence }\end{array}$ & 47 \\
\hline Incidence percentage & $22.38 \%$ \\
\hline
\end{tabular}

\begin{tabular}{|l|l|l|}
\hline Parity & Frequency & Incidence of USD \\
\hline $1-2$ & 63 & 9 \\
\hline $3-4$ & 86 & 16 \\
\hline $5-6$ & 34 & 19 \\
\hline 7 or more & 27 & 3 \\
\hline
\end{tabular}

\begin{tabular}{|l|l|l|}
\hline Age group & Frequency & Incidence of USD \\
\hline $18-25$ & 81 & 13 \\
\hline $25-38$ & 106 & 27 \\
\hline $38-50$ & 23 & 7 \\
\hline
\end{tabular}

\begin{tabular}{|l|l|}
\hline Caesarean section & Incidence of USD \\
\hline 1 C-section & 21 \\
\hline 2 C-sections & 13 \\
\hline 3 C-sections & 9 \\
\hline 4 C-sections & 4 \\
\hline
\end{tabular}

\section{DISCUSSION}

Lower segment caesarean section comes with certain complications; one of these complications is scar dehiscence. Fortunately, the occurrence is rather rare; however, it is still noteworthy since the complication can be a major factor in increasing morbidity and mortality rate. Uterine scar dehiscence may be defined as disruption of the uterine muscle with integral uterine serosa. Frequency of scar dehiscence around the globe regardless of the cause is found to be $0.6 \%{ }^{13}$.

Various risk factors further increase the rate of scar dehiscence. For instance, it is estimated that occurrence of scar dehiscence may be observed in up to $3 \%$ cases in vaginal birth after $\mathrm{C}$-section ${ }^{14}$. Women who have had more than three lower segment caesarean sections are found to be at a $63 \%$ higher risk of scar dehiscence, in comparison to $0.39 \%$ of those with less than three LSCS. Intrapregnancy gap also plays a vital role in determining the incidence of scar dehiscence. It is stated in a study that a gap of less than 24 month between two pregnancies can increase the chances of scar dehiscence from $45.1 \%$ to $66.7 \%{ }^{15}$.

A preterm delivery or a uterine infection may cause the weakening of the uterine wall. This too, is found to be a risk factor in the incidence of USD. A preterm delivery itself is stated to be an independent risk factor by a study, which further pronounces the occurrence to increase from $15.2 \%$ to nearly a double of $33.3 \%$ due to this independent risk factor. A sole layer closure of cesarean slit is also a distinguished risk factor contributing to higher incidence of scar dehiscence ${ }^{16}$.

A case study conducted by Abdelazim et al, further confirms that a inter-pregnancy gap of 6 months was found to be a major cause of USC. It also states that gestation at
30 weeks also played a vital role in weakening the uterine wall and ultimately resulted in a USD ${ }^{17}$.

VBAC is a controversial topic when talking in terms of USD. Where one study states that VBAC is a protective factor and can reduce the occurrence of USD, another concluded that it increases the incidence of scar dehiscence ${ }^{18}$. Trial of labour is also observed to increase the incidence by $0.3 \%$ and therefore it is essential to screen for USD during TOL ${ }^{19}$.

\section{CONCLUSION}

With an increasing number of caesarean sections, the risk of USD has increased considerably. The incidence of scar dehiscence was found to be $22.38 \%$ in this study which includes risk factors like inadequately short intra-pregnancy time interval, preterm delivery, VBAC and trial labour. USD can result in higher morbidity and mortality of the mother and child therefore its early detection and management is crucial to the patient's life.

\section{REFERENCES}

1. Baron J, Weintraub AY, Eshkoli T, Hershkovitz R, Sheiner E. The consequences of previous uterine scar dehiscence and cesarean delivery on subsequent births. Int $\mathrm{J}$ Gynaecol Obstet. 2014;126:120-2. [PubMed] [Google Scholar]

2. Mumtaz S, Bahk J, Khang YH. Rising trends and inequalities in cesarean section rates in Pakistan: Evidence from pakistan demographic and health surveys, 1990-2013. PLoS One 2017; 12(10): e0186563.

3. Sawada M, Matsuzaki S, Nakae R, Iwamiya T, Kakiga-no A, Kumasawa K, Ueda Y, et al. Treatment and repair of uterine scar dehiscence during cesarean section. Clin Case Rep. 2017;5:145-9. [PMC free article] [PubMed] [Google Scholar]

4. Royal College of Obstetricians and Gynaecologists. Birth after previous caesarean birth. Green-top guideline. 2007(45).

5. Health and Social Care Information Centre. NHS Maternity Statistics - England, April 2012 to March 2013: Provider level analysis. [Leeds]: HSCIC; 2013 Available at: http://www.hscic. gov.uk/catalogue/PUB12744

6. Welsh Government. Maternity Statistics, Wales: Method of Delivery, 2004-2014. SDR 210/2014. Cardiff: Welsh Government;2014 Available at: http://gov.wales/docs/statistics/2014/141202-maternitymethod-delivery-2014-en. Pdf.

7. Garza P. Spontaneous Uterine Rupture: report of two cases. Cir 2012;80:78-82.

8. Macones GA, Cahill AG, Stamilio DM, Odibo A, Peipert J, Stevens EJ. Can uterine rupture in patients attempting vaginal birth after cesarean delivery Be predicted? Am J Obstet Gynecol. 2006;195(4):1148-52.

9. Bano R, Mushtaq A, Adhi M, Saleem MD, Saif A, Siddiqui A, et al. Rates of cesarean sections and trials and success of vaginal birth after caesarean section in secondary acre hospital. J Med Pak Assoc 2015; 65(1): 81-85.

10. The National Institute for Health and Clinical Excellence (NICE) guidelines for cesarean section (CG132). 2011. Retrieved from: www.ncbi.nlm.nih.gov/books/NBK115309

11. Women's Health Committee. Birth after previous caesarean section. approved by RANZCOG Board and Council. 2015. Retrieved from: https://www.ranzcog.edu.au/ranzcog_site/ media/ranzcog-media/Women\%27s\%20Health/Statement\% 20and\%20guidelines/Clinical-Obstetrics/Birth-after-previousCaesarean-Section-(C-Obs-38)-Re-write-July2015_1.pdf?ext=.pdf

12. 7.Bashiri A, Burstein E, Rosen S, Smolin A, Sheiner E, Mazor M. Clinical significance of uterine scar dehiscence in 
women with previous cesarean delivery: prevalence and independent risk factors. J Reprod Med. 2008;53(1):814.pubmed.

13. Khan F, Khurshid S, Zafar S, Zainab S, Zakria M, Asif S. View of Scar Dehiscence in Patients Presenting with Scar Tenderness Due to Previous One Cesarean Section [Internet]. Jsogp.net. 2020. Available from: http://jsogp.net/index.php/jsogp/article/view/250/275

14. Kumar I, Verma A, Matah M, Satpathy G. Utility of multiparametric $\mathrm{MRI}$ in Caesarean section scar characterization and preoperative prediction of scar dehiscence: a prospective study. ActaRadiologica. 2016;58(7):890-896.

15. Akbar A, Zaineb S, Mahboob S, Khan S. INCIDENCE AND RISK FACTORS FOR SCAR DEHISCENCE IN LOWER SEGMENT CESAREAN SECTION. PAFMJ [Internet]. 30Jun.2020 [cited 8Dec.2020];70(3):862-0. Available from: https://mail.pafmj.org/index.php/PAFMJ/article/view/4680

16. Ramadan, M., Kassem, S., Itani, S., Sinno, L., Hussein, S., Chahin, R., \&Badr, D. (2018). Incidence and Risk Factors of
Uterine Scar Dehiscence Identified at Elective Repeat Cesarean Delivery: A Case-Control Study. Journal Of Clinical Gynecology And Obstetrics, 7(2), 37-42.

17. Abdelazim IA, Shikanova S, Kanshaiym S, Karimova B, Sarsembayev M, Starchenko T. Cesarean section scar dehiscence during pregnancy: Case reports. J Family Med Prim Care. 2018 Nov-Dec;7(6):1561-1565. doi: 10.4103/jfmpc.jfmpc_361_18. PMID: 30613559; PMCID: PMC6293899.

18. 3. Kwong F, Hamoodi I. Postnatal diagnosis of an occult uterine scar dehiscence after three uncomplicated vaginal births after Caesarean section: A case report. Case Reports in Women's Health. 2020;27:e00203.Sawada M, Matsuzaki S, Nakae R, Iwamiya T, Kakigano A, Kumasawa K, Ueda Y, Endo M, Kimura T. Treatment and repair of uterine scar dehiscence during cesarean section. Clin Case Rep. 2017 Jan 19;5(2):145-149. doi: 10.1002/ccr3.766. PMID: 28174640; PMCID: PMC5290508. 